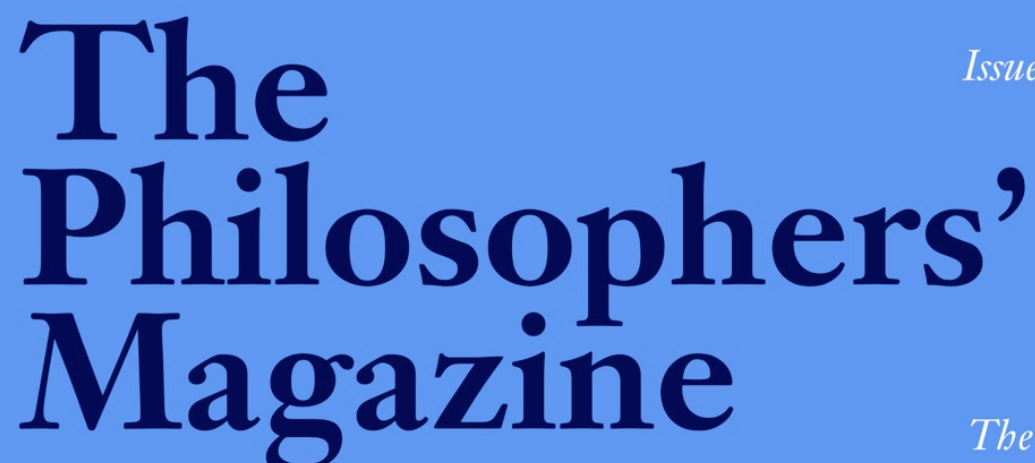

Issue 91, 4th Quarter 2020

UK $£ 6.99$ US $\$ 8.99$

The Tedium of Immortality

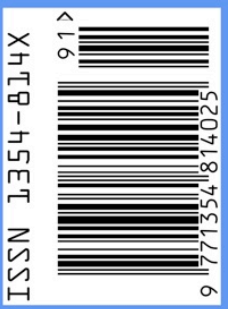

Summer of Protests Moral Grandstanding Women Who Hate Women

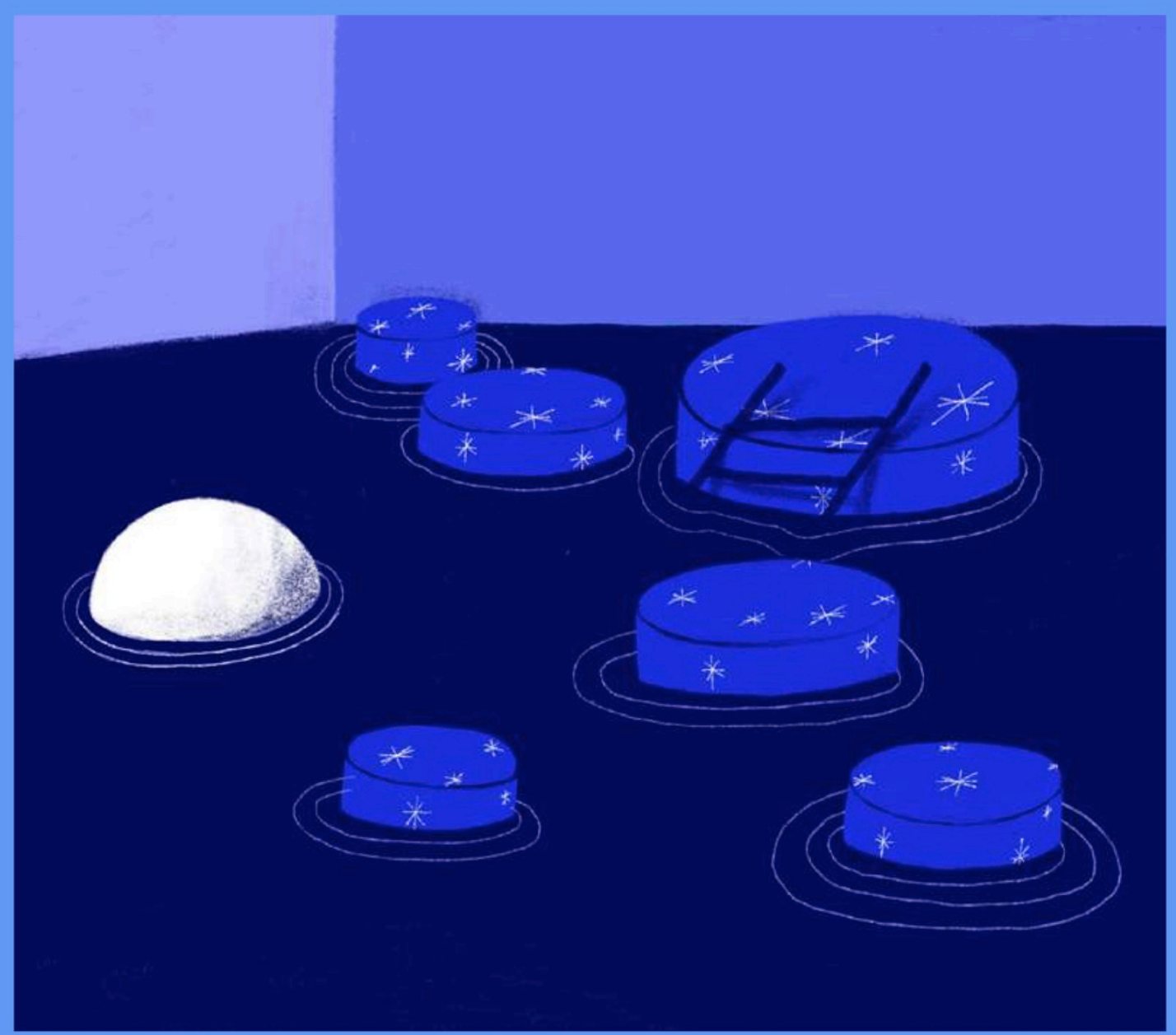




\section{LiteraryReview}

FOR PEOPLE WHO DEVOUR BOOKS

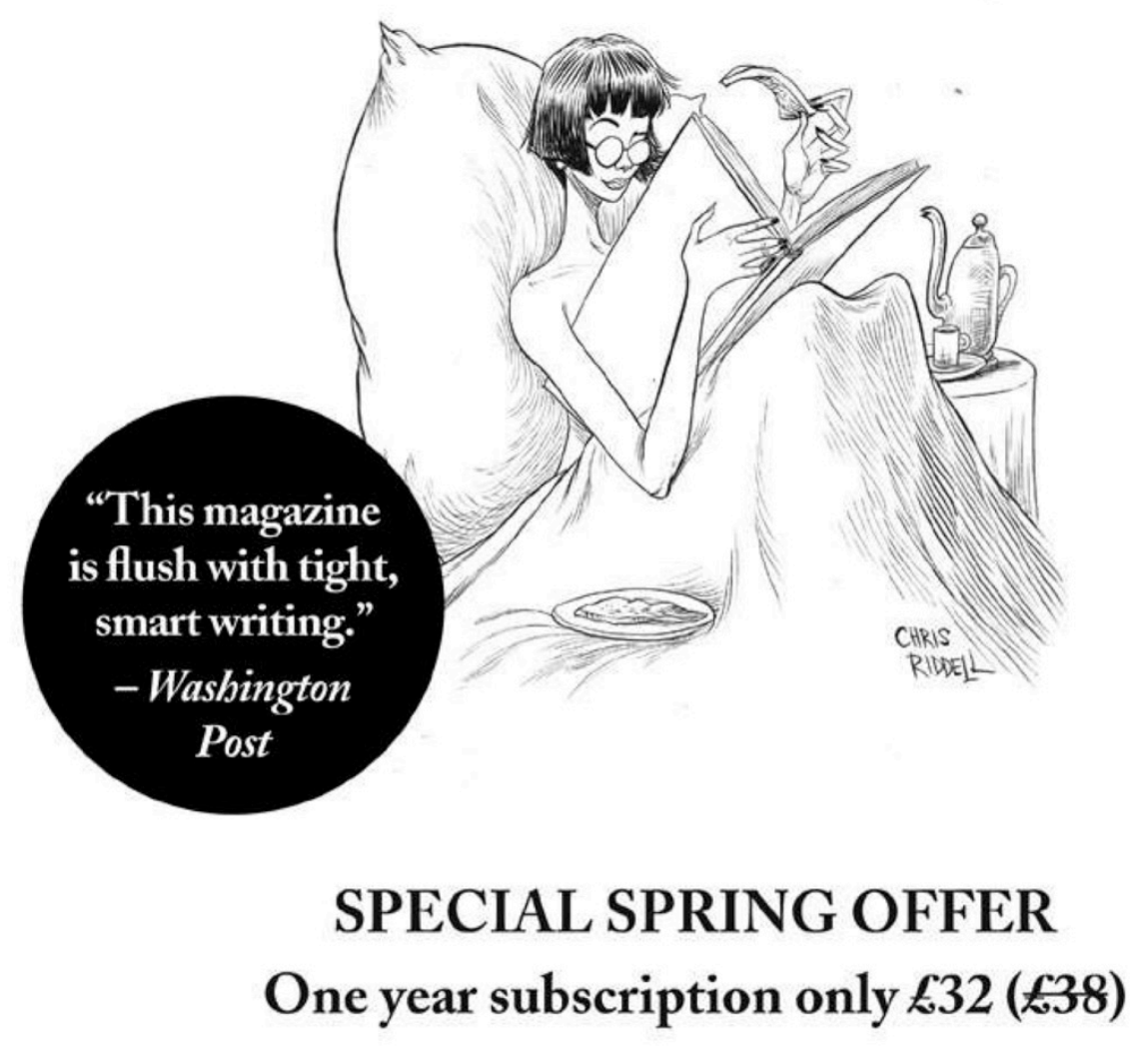

Literary Review offers sixty-four pages of lively and authoritative reviews each month by leading contemporary writers and thinkers. All subscribers receive free access to our app, website and online archive dating back to 1979 .

Offer prices: UK: $£ 32$ (£38) Europe/USA: $£ 39.99$ (£48) ROW: $\$ 49.99$ (£65)

To subscribe go to www.literaryreview.co.uk/subscribe or call 01778395165 and use the code PHILOSOPHERS 


\section{Issue 91 4th Quarter 2020}

Editor James Garvey/Jean Kazez Founding Editor Julian Baggini Reviews Editor Jean Kazez Aesthetics Editor Aili Bresnahan Epistemology Editor Daniel O'Brien Editorial Associate Kerrie Grain Art Director Adele Juraža Cover Image Ana Teresa Printed by Lavenham Press

Editorial Advisory Board Miranda Fricker, Simon Glendinning, Daniel D. Hutto, Susan James, Charlotte Knowles, David Papineau, Nina Power, Anthony Price, Thomas Quinn, Jonathan Rée, Richard Schoch, Barry C. Smith and Jonathan Wolff

\section{UK Distribution}

Central Books

99 Wallis Road, London, E9 5LN

02089854854

\section{North American Distribution}

Source Interlink

275000 Riverview Center Blvd., Bonita Springs, Florida 34134 (239) 949-4450

\section{Subscriptions}

North America 800-444-2419

pdcnet.org/tpm/The-Philosophers'-Magazine Everywhere else 01442820580 webscribe.co.uk/magazine/tpm Digital, iPhone and Android exacteditions.com/read/tpm

\section{Abstracting and Indexing} Indexed by Philosopher's Research Index (Philosophy Documentation Centre) and The Philosopher's Index

(c) 2020 Apeiron Ltd and contributors

ISSN 1354-814X (print) ISSN 2048-4674 (online)

All views expressed in The Philosophers' Magazine represent those of the authors of each article and do not necessarily reflect those of the editors or publisher.

\author{
Advertising \\ advertising@philosophersmag.com \\ philosophersmag.com \\ editor@philosophersmag.com \\ @ philosophersmag \\ facebook.com/PhilosophersMag/ \\ appstore.com/thephilosophersmagazine
}




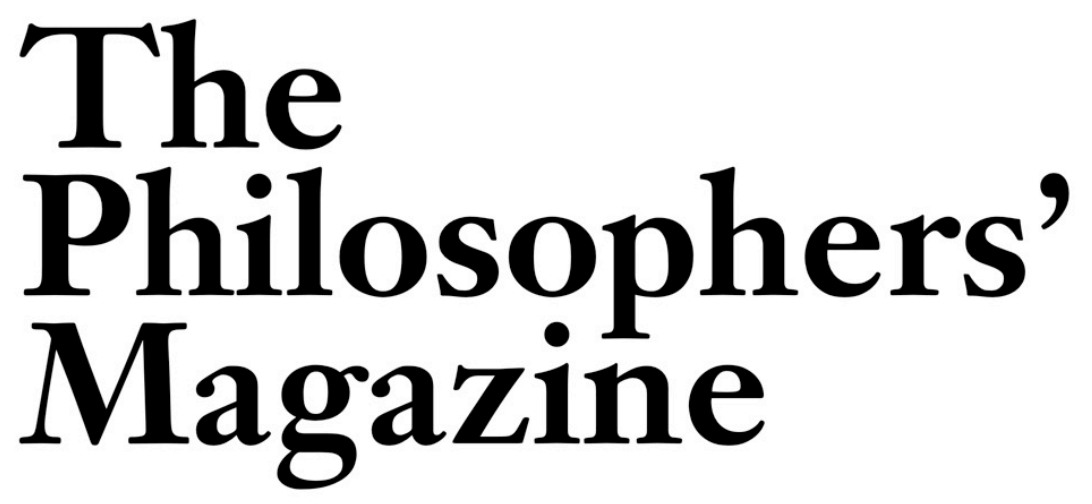

5 Editorial

fean Kazez

6 Autumn News

Pandemic Postcards

11 Opinion

Philosophy, In a Sense

Katie Behrens and Constantine Sandis

13 Living the Life of the Mind

Charlotte Knowles

16 The Skeptic

Wendy M. Grossman
18 Thoughts

Introduction

20 Democratic Theory After Sixth Grade fason Brennan

26 What to Do with Dead Monuments Elizabeth Scarbrough

33 Summer of Protest Alida Liberman

40 Resistance Training Alex Madva

46 Moralising to Impress fustin Tosi and Brandon Warmke

53 Female Misogyny Berit Brogaard

60 A Magical Syllabus Emily Thomas

65 Frank Ramsey: A Sheer Excess of Powers Cheryl Misak 
70 Forum: Getting Old

Introduction

72 Life is Good

Fobn Martin Fischer

78 The Year I Got Old William B. Irvine

84 Beyond Gray Hair and Wrinkles Christine Vitrano

89 Tragic Life Endings and Covid-19 Policy August Gorman

94 The Gift of Death foshua Glasgow

99 Strength in Old Age Gail Weiss
104 Reviews

Introduction

106 (Don't) Get Well Soon

fean Kazez

108 Sick Souls, Healthy Minds: How William James Can Save Your Life reviewed by Tess Varner

111 Entitled: How Male Privilege Hurts Women reviewed by Serene Khader

115 Simply Nietzsche reviewed by Maudemarie Clark and Andrew Winer

119 Philosophical Disquisitions $Q$ and $A$ with Fohn Danaher 


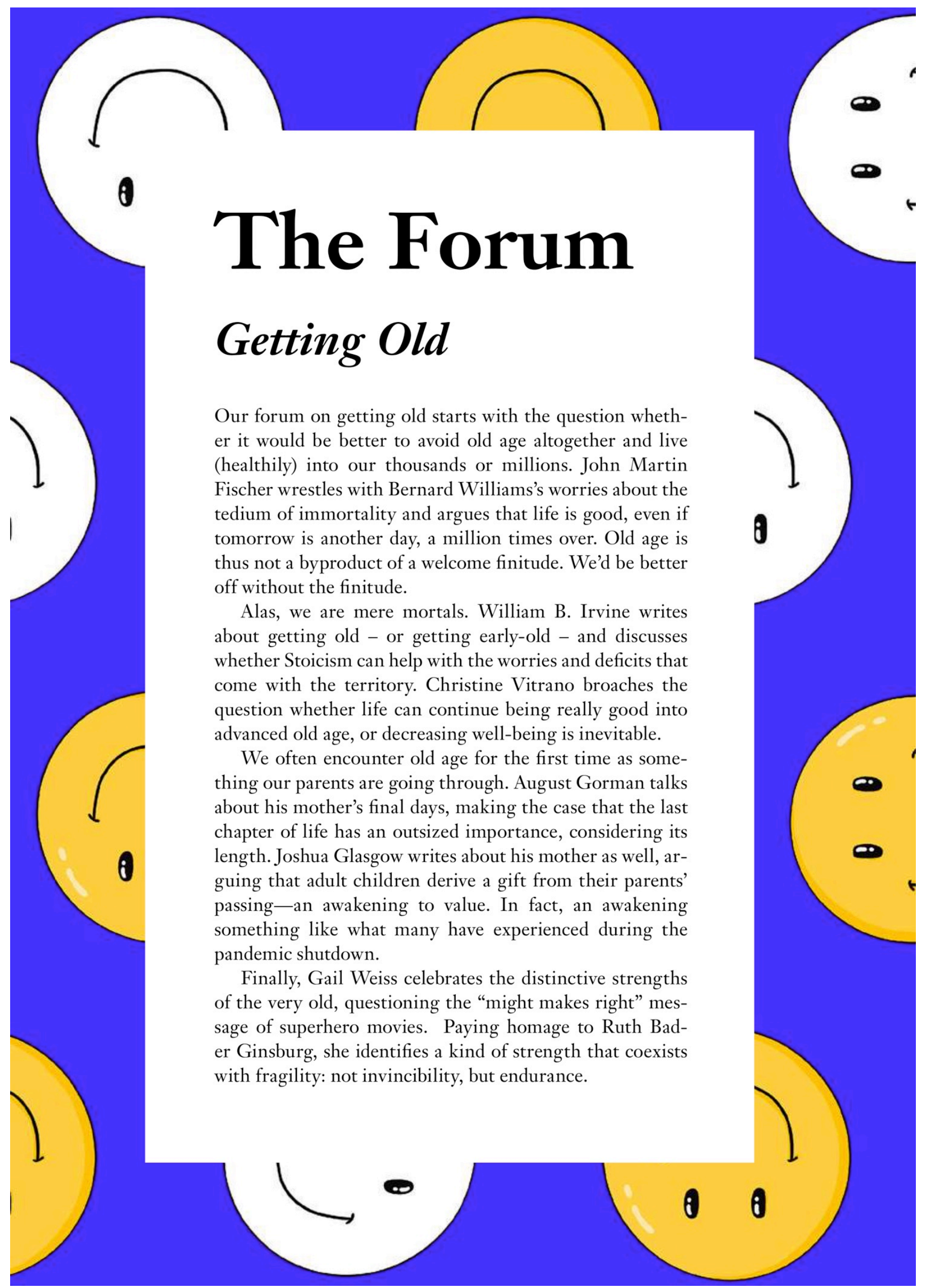

Printed for gorman.august from The Philosophers' Magazine - 4th Quarter 2020 at exacteditions.com. Copyright $\odot 2020$ 


\title{
Tragic Life Endings and Covid-19 Policy
}

\author{
August Gorman explains why last days matter more
}

My vibrant fifty-nine-year-old art teacher mother was diagnosed with a rapidly growing terminal brain tumour during the height of the Covid-19 pandemic in the U.S. At her acute rehab centre, where she learned to walk and talk again, following surgery to slow the speed of the tumour's growth, I wasn't permitted to visit her. The limited staff the rehab operated with had to deprioritise things like helping my mom charge her phone, leaving me often unable to reach her. I tried to send her comfort items, like a chemotherapy hat to cover her scar, or an accessible paintbrush so she could paint despite her tremors, but shipping would take months as Amazon was prioritising medical supplies and household essentials. Tragically, my mom's situation was hardly unique; restrictions on hospital and nursing home visitors, deliveries, travel, and large gatherings have impacted the way that hundreds of thousands of people's lives have come to an end.

From one vantage point, these measures are all completely reasonable, though, of course, it's unfortunate how they had to play out in my mom's situation. Lack of visitation, limited staffing, and prioritisation of shipping only essential goods were measures put in place to prevent people from dying. While there might be a debate about which lives to prioritise when we can only prevent a certain number of people from dying, these measures promised to decrease Covid-19's overall casualty rate saving a quite significant number of cumulative years of life that would otherwise have been lost to the disease. Wherever we can, we might think, we should always prioritise preventing deaths.

\section{The ending can transform the gestalt of a whole narrative}

I'm not convinced that the sloganistic version of this moral rule is obviously right, though. Though we rarely talk about it, there are lots of choices we have made in setting up our society that allow for us to enjoy something that enriches our general quality of life even though it will mean an increase in the cumulative years of life lost among us all. For example, we accept that people will drive cars, despite the fact that no one is in the dark about the inevitability of fatal motor vehicle accidents (over a million die each year, worldwide). Clearly, there are some trade-offs we are willing to make. Consider, then, the following trade- 


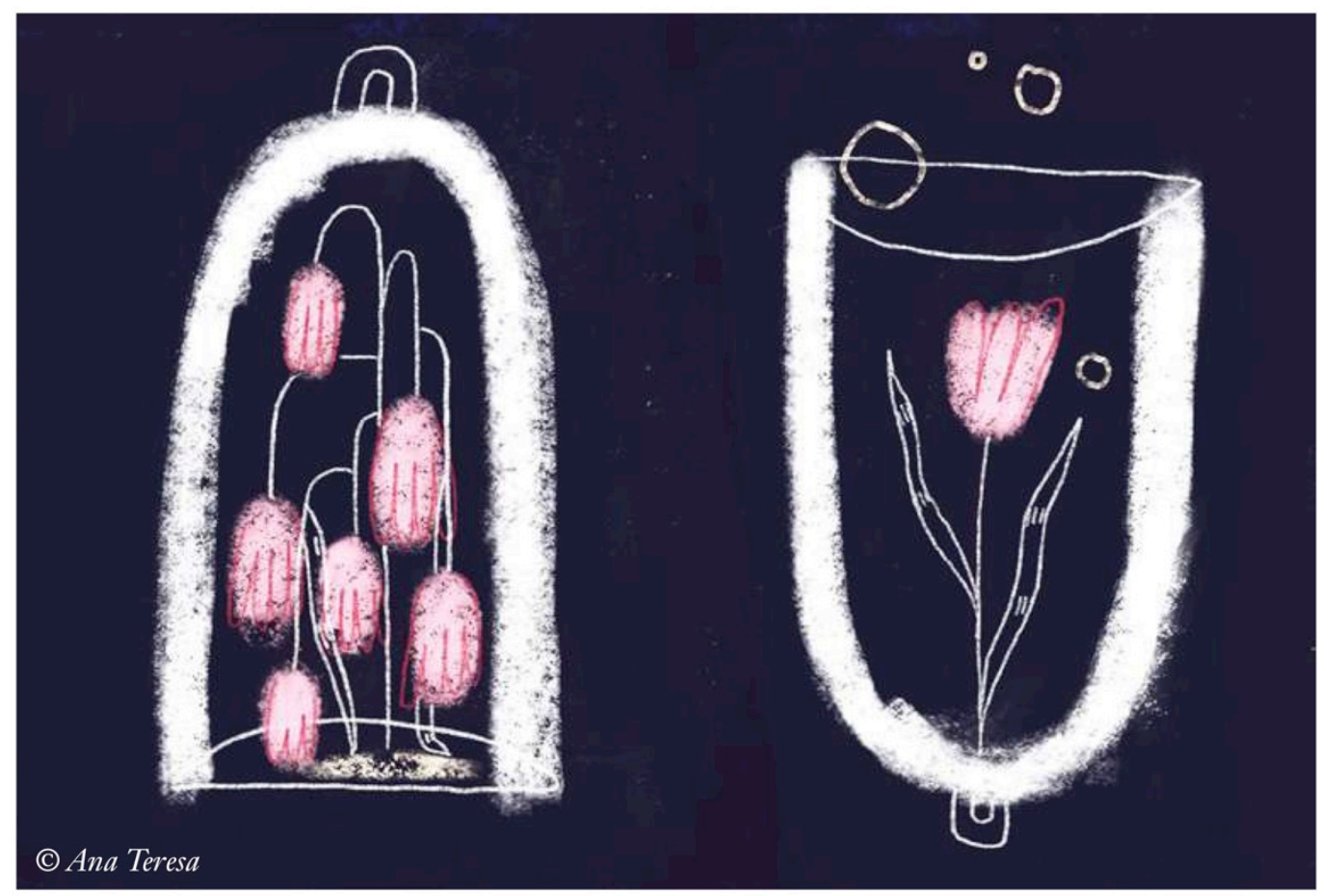

off: Would you rather live for 30 more years and die scared, confused, and alone with your loved ones worrying about you and not getting to say goodbye, or would you rather live for only another 29 years and 51 weeks and die peacefully, holding the hands of your family members? Most people, I think, would choose the slightly shorter life with the better ending. Many people might even be willing to make bigger trade-offs in terms of time lived in order to have a life with a good ending. Even though the life would be shorter, all things considered, it would be a better life.

This fact should make us think twice about whether or not it's really so obvious that we ought to always prioritise extending some people's lives at the cost of giving some people who are dying anyway a particularly lonely and tragic end to life.
How could it be, though, that such a short amount of time (the final week of your life, let's say) could have such a large impact on how well your life goes? In order to answer that question, we'll have to look at two different ways of thinking about what determines how well a life goes.

On the most common kind of view, what makes your life go well is thought to be determined by adding up all of the moments that contribute to your well-being that you have throughout your life. The order doesn't matter. How good your life is as a whole is simply a sum of how good each of its moments are, whether the goodness of each moment is measured in terms of happiness, the degree to which your desires are satisfied, or something else. On a non-additive view, by contrast, we can only understand how good a moment in your life 
is by reference to the role it plays in your life considered as a whole. The value of the lifetime, rather than the value of a moment, is the most fundamental unit of measurement.

It is only when we assume an additive view that the great importance that the endings of our lives hold for us can seem puzzling. If we are just adding up how good moments are, then no matter how bad that final week is, it is only 168 hours of your life, which is counterbalanced by the value of the other hundreds of thousands of hours you've lived. The last week, then, should barely make a dent one way or another to how good your life is overall, no matter how good or bad it is. Instead, I think we should accept a version of the non-additive view where the moments of a person's life fit together not as a math equation, but as intertwined elements of a sort of story.

\section{The last week is 168 hours of your life}

Most of us are quite invested in the stories our lives tell. We want to learn from our mistakes, find a career we feel like we're meant to pursue, end up with the right person, and we want for our hard work to pay off. We want to feel like our lives are going somewhere and that that somewhere is somewhere that we want to go. These things all have to do with not just how good the moments are individually, but how they fit together into some sort of cohesive whole. The narratives of our lives, it would seem, have real value for us. This is not to say, though, that what would make for a good novel or a good opera would necessarily make for a good life. A heartbreaking tale of a hero who meets a cruel fate might be a compelling tale, but that does not make it a story that we'd like to live out. Nevertheless, the poetic or personal resonance that living out a certain life-story has for us does seem to matter to us. Whether our life stories end up having this kind of resonance for us can play a large role in how good our lives turn out to be, overall.

Suppose that a god appears to you and somehow lets you experience every potential way that your life could go from here on out and choose which you would most prefer to live out. Your deliberation about which life to lead might involve a number of different factors. If you're at all like me, though, many of the most important factors would involve knowing how, in each possible life, the stories of the various aspects of your life would play out in all of their particularities. I would want to know, for example: Do I carry on my mom's creative lega$\mathrm{cy}$, learning to paint, and someday painting something that so perfectly expresses my point of view? Do my partner and I continue to grow and mature in our relationship, learning from each other in the ways it always seemed we would?

But the additivist would have to insist that we could just as well skip this whole process of experience, deliberation, and reflection on what just the right way would be for the stories of our lives to play out. Instead, anyone who had access to the raw numbers - the levels of happiness, or strengths and numbers of desires satisfied that I would have at each moment of my life - could assess a potential life's value for us, without even knowing anything about the details. Without even knowing how you 
would rank the potential lives, a person with the raw numerical data could choose the best life for you, simply adding up the scores of each moment for each potential life and picking the highest valued option for you. In fact, according to the additivist, you should probably prefer this method of choosing as you may very well be wrong about which life would be best for you - the higher sum might not line up at all with the life that seems to you to contain the perfect culmination of all of your trials and tribulations.

The additivist, it seems to me, misses something crucial by focusing narrowly on quantifiable measures of momentary well-being and neglecting to take into account how the stories of our lives strike us as individuals and what our preferences are over which story is being written. As a consequence, I think the additivist also misses something about just how crucial the ending of a life is by failing to take into account features about our preferences over how our stories end. An ending (as anyone who has seen an M. Night Shyamalan movie can attest to) can transform the gestalt of an entire narrative. Life narratives, to some degree, are no exception. To account for the badness of a certain last week of life in terms of the happiness levels at each of the last 168 hours is to miss the fact that much of that last week's value is value it has by virtue of its being a particular life's ending. As for the values of different endings, there is ultimately no arbiter beyond what the people whose life-stories they are would want for themselves.

I have argued that we should reject the additivist view, instead taking an approach that makes room for considering the value of moments in terms of the role they play in the person's entire life story. Given the special value that endings have for narratives, we can make sense of the fact that people have strong interests in how the end of their lives play out. These interests can be strong enough that many people would make a trade-off to accept a shorter length of life for the opportunity to have their lives end how they'd most want them to, usually surrounded by their favourite things and people, being comforted by the ones who love them the most. This should make us more hesitant to accept public health policies that put restrictions on the essential comforts usually provided to people nearing the end stages of their lives.

\section{Most of us are quite invested in the stories our lives tell}

That said, I certainly don't want to overstate the implications of this view in the context of a pandemic. It is my belief that these measures that significantly impact life endings should not be implemented indefinitely while other efforts to manage the pandemic are enforced only haphazardly. But if, for example, a blanket ban on hospital visitation for a month or two were the only way to significantly curtail the pandemic, it would certainly be worth doing. We should keep in mind that each person who lives an unexpectedly short life due to dying from a pandemic disease also experiences a reduction in lifetime well-being, as well as their loved ones, and this must certainly be reckoned with. Certainly almost no one would want 


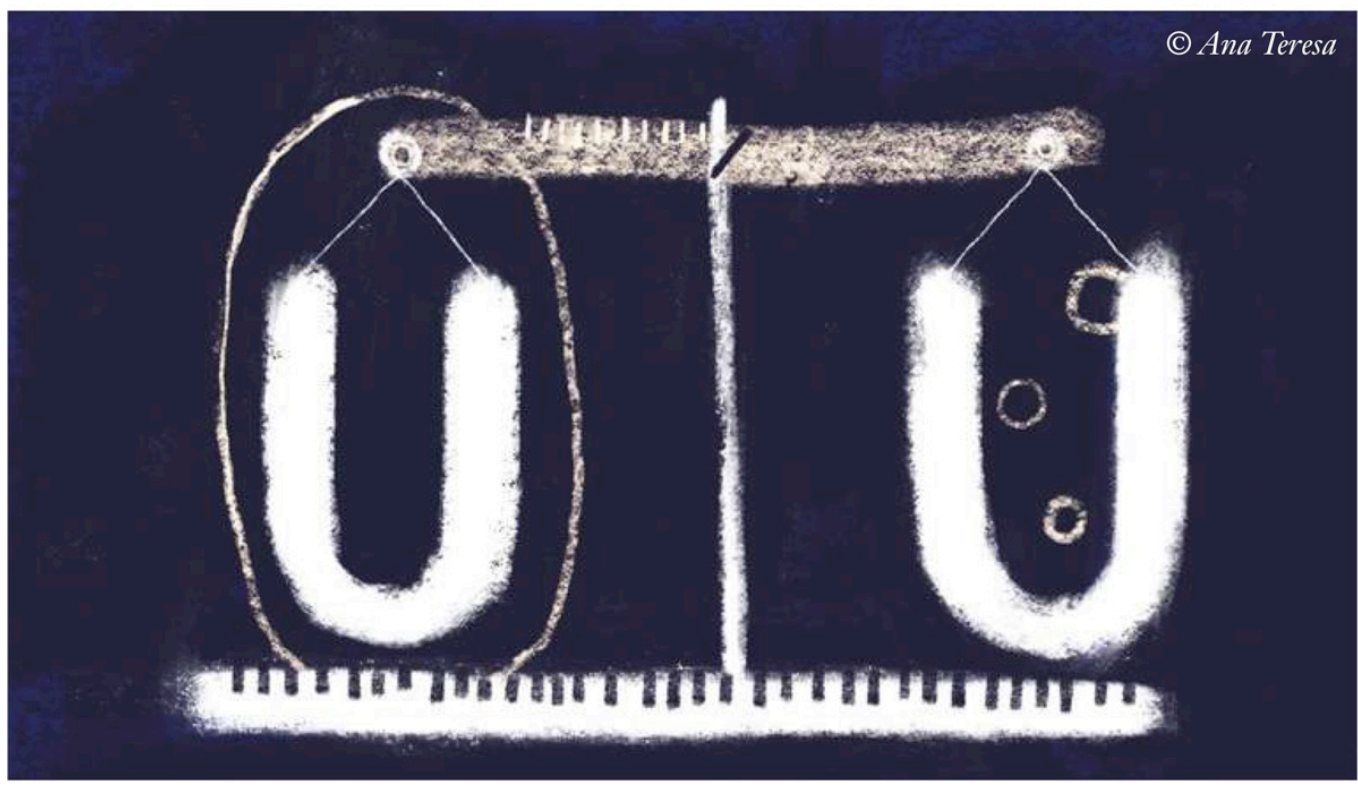

an end to their life story where the occasion of their dying ushers in a wave of disease and death for those around them.

But even in the case where the restrictions that prevented me from being able to provide my mother with comfort would be deemed absolutely necessary, I think it's important that we grapple with the enormity of what we've given up. Additivist assumptions about well-being underlie many of the kinds of metrics that inform policy as well as many of the simple-sounding sloganistic arguments about the obviousness of the sacrifices we must make. We might be able to somewhat cleanly measure how important it is to be able to ship facemasks to a country by measuring the risk of transmission and the happiness possibly contained in the estimated life years lost, but I worry that the kind of thing that we lose in the fray is the value an accessible paintbrush might have for someone who might have been leaving her last mark. In the wake of the Covid-19 pandemic, many of us will grieve not only the loss of lives but also these more subtle and hard to articulate losses.

When crisis hits, we must of course move rapidly, but we shouldn't pretend that crude metrics suffice just because they are easier to wield. We must quickly brainstorm what we all would want for ourselves that ensures that we take into account our desires to maintain our humanity. During a time when it is too easy for people to be reduced to numbers, we should strive to ensure that our value as individuals with complete life-stories stays in clear view when we face the end.

August Gorman is a Values and Public Policy Postdoctoral Fellow at the University Center for Human Values at Princeton University. He is a philosopher whose work focuses on mental health ethics, well-being, moral responsibility, and the philosophy of death. 